\title{
Natural killer type 2 bias in remission of multiplesderosis
}

\author{
Kazuya Takahashi, ${ }^{1}$ Sachiko M iyake, ${ }^{1}$ Takayuki Kondo, ${ }^{1}$ Keiji Terao, ${ }^{2}$ \\ M egumi H atakenaka, ${ }^{3}$ Shuji Hashimoto, ${ }^{3}$ and Takashi Yamamura ${ }^{1}$
}

1D epartment of Immunology, N ational Institute of Neuroscience, N ational Center of Neurology and Psychiatry,
Kodaira, Tokyo, Japan
2Tsukuba Primate Center for M edical Science, I baraki, Japan
3D epartment of N eurol ogy, Tenri H ospital, N ara, Japan
Address correspondenceto: Takashi Yamamura, Department of Immunology, N ational Institute of N euroscience,
NCNP, 4-1-1 Ogawahigashi, Kodaira, Tokyo 187-8502, Japan.
Phone: 81-423-46-1723; Fax: 81-423-46-1753; E-mail: yamamura@ncnp.go.jp.

Received for publication November 20, 2000, and accepted in revised form January 15, 2001.

Multiple sclerosis (MS) is an autoimmune disease characterized by clinical relapse and remission. Because of the potential role of natural killer (NK) cells in the regulation of autoimmunity, we have examined cytokine profileand surface phenotype of NK cells in the peripheral blood of MS. Here we demonstrate that NK cells in the remission of MS are characterized by a remarkable el evation of IL-5 mRNA and a decreased expression of IL-12R $\beta 2$ mRNA, as well as a higher expression of CD 95. M oreover, the NK cells from MS in remission produced much larger amounts of IL-5 than did those from controls after stimulation with phorbol myristate acetate (PM A) and ionomycin. Thesefeatures arereminiscent of those of NK type 2 (NK2) cells that can be induced in a condition favoring functional deviation of T cells toward Th2. Remarkably, the NK cells losethe NK2-like property when relapse of MS occurs, but regain it after recovery. Wealso found that NK 2 cells induced in vitro inhibit induction of Th1 cells, suggesting that the NK2-like cells in vivo may al so prohibit autoimmune effector T cells. Taken together, it is possiblethat NK cells play an active rolein maintaining theremission of MS.

This article was published online in advance of the print edition. The date of publication is availablefrom the JCI website, http:// www.jci.org. J. Clin. Invest. 107:R23-R29 (2001).

\section{Introduction}

Currently it is recognized that various types of regulatory cells can actively suppress autoimmune diseases. In experimental autoimmuneencephal omyelitis (EAE) (1-4), the prototype autoimmune disease mediated by Th1 cells, cell depletion or adoptive transfer studies haveestablished the role of regulatory $\alpha \beta T$ cells $(1,2)$, $B$ cells (3), and NK cells (4) in theregulation of the disease. However, it remains obscure how deeply involved are such regulatory cells in human Th1-mediated autoimmune diseases like multiple sclerosis (MS). M ost patients with MS enjoy clinically stableperiods of variable duration (remission), although interrupted unpredictably by occurrence of relapse. It is interesting to consider whether regulatory cells may play an active role in maintaining the remission of $\mathrm{MS}$. H owever, to our knowledge, no substantial studies exist that could provide insights into this intriguing question regarding regulatory cells. In this study, weattempted to characterize the functional phenotype of NK cells in the remission and relapse of $\mathrm{M} S$ because of the downregulatory role of NK cells demonstrated in EAE (4).

A recent study has shown that human NK cells are able to polarize in vitro into two functionally distinct subsets NK typel (NK1) or NK2 (5), analogous to T-cell subsets Th1 or Th2 (6, 7). N amely, NK cells grown in a culturecondition favoring Th1 deviation (culture with IL-12 and anti-IL-4 mAb) would differentiateinto NK1 cells producing IFN- $\gamma$ and IL-10, whereas NK cells grown in a Th2 condition (with IL-4 and anti-IL-12 $\mathrm{mAb}$ ) differentiate into N K2 cells predominantly producing IL-5 and IL-13 (5). Expansion of NK2-likecells producing IL -5 and IL-13 have recently been observed in IFN - $\gamma$-knockout mice (8), indicating that NK cells could functionally polarizein vivo in rodent. However, it remains unknown whether the N K1/N K2 concept could berelevant in vivo in human and, if so, what roles NK1 or NK 2 cells would play in the adaptive immune responses in health or disease. On the basis of these backgrounds, we have focused our efforts on characterizing the cytokine profile of $\mathrm{NK}$ cells ex vivo.

Herewe demonstrate, for the first timeto our knowledge, that remission (but not of relapse) of M S is associated with a strong bias of $\mathrm{NK}$ cells toward producing IL-5. Together with the lower expression of IL-12R $\beta 2$ chain and a higher surface expression of CD 95 (Fas) by NK cells, weinterpret theoverall profileof the NK cells in remission as highly consistent with that of NK2 cells (5). With additional data from in vitro experiments, we proposethat theN K2-likecells play an active rolein the maintenance of clinical remission of MS by inhibiting autoimmuneTh1 cells. 
Table 1

Detection frequency of cytokine and cytokine receptor messages in NK cells

\begin{tabular}{lcccccc}
\hline & IFN $-\gamma$ & IL-12R & IL-5 & IL-13 & IL-10 & TGF- $\beta 1$ \\
MS in remission & $7 / 8$ & $7 / 8$ & $9 / 9$ & $2 / 18$ & $2 / 5$ & $3 / 18$ \\
Healthy subjects & $7 / 8$ & $7 / 8$ & $7 / 8$ & $0 / 17$ & $2 / 5$ & $2 / 10$
\end{tabular}

Cytokine and cytokine receptor messages expressed in NK cells were evaluated by RT-PCR. The data represent the number of positive samples divided by the number of total samples.

\section{Methods}

Subjects. All the M S patients (six men and 16 women, ages $39 \pm 12.4$ years) were diagnosed on the clinical criteria (9) and by M RI. Herewe defined "MS in remission (MS-rem)" as those who have been clinically stable without any immunosuppressive medications for more than 3 months and "M S in relapse (M S-rel)" as those who have developed an apparent exacerbation within an interval of 1 week. The presence of active lesions in MS-rel was confirmed with gadolinium-enhanced M RI in all cases. To monitor M S-rem, M RI scans were repeated every 3-6 months. Gadolinium enhancement was not routinefor M S-rem, but it was performed when the occurrence of relapse was suspected. As a control for MS-rem, we examined sex- and age-matched controls, including healthy subjects (HS) (five men and 11 women, ages $41.8 \pm 10.2$ years), other neurological diseases (OND) (two men and five women, ages $46.4 \pm 7.7$ years) and other autoimmune diseases (OAI) (two men and five women, ages $45.3 \pm 16.1$ years). OND include Parkinson disease $(n=4)$, spinocer ebellar degeneration $(n=2)$ and amyotrophic lateral sclerosis $(n=1)$, whereas OAI are composed of thyroiditis ( $n=5)$, myasthenia gravis $(n=1)$ and inflammatory demyelinating polyneuropathy $(n=1)$. N oneof the subjects weregiven corticosteroid or immunosuppressive agents when the study was conducted.

Antibodies. For immunofluorescence analysis, the following fluorescence or biotin-labeled $m A b$ 's were used: anti-human CD3-FITC, CD3-PerCP, CD56-FITC, CD56-PE, IFN- $\gamma$-PE, IL-4-PE (Becton Dickinson Immunocytometry Systems, San Jose, California, USA), and anti-human CD 95-biotin (PharM ingen, San Diego, California, USA). mAb's to IL-4 (4F2/5A4), IL-12 (C8.6) (DIACLONE Research, Besancon, France), and IL-5 (R\&D Systems Inc., M inneapolis, M innesota, USA) were used for neutralizing respectivecytokines in vitro. Streptavidin-Cychrome (PharM ingen) was used as the second-step reagent for flow fluorocytometry.

Purification of NK cells and generation of NK subset. NK cells and T cells were negatively selected from PBM Cs using the NK Isolation Kit and Pan T Cell I solation Kit (both from Miltenyi Biotech, Gladbach, Germany), respectively. The isolated cell populations were found to yield greater than $98 \%$ purity when assessed by flow fluorocytometry. N K1 and NK2 cell populations were induced in vitro as described previously (5). In brief, PBM Cs $\left(2 \times 10^{7} / \mathrm{ml}\right)$ were seeded onto 24 -well plates together with X-irradiated RPM 18866 cells $\left(4 \times 10^{6}\right.$ $/ \mathrm{ml}$ ) (a kind gift from $\mathrm{G}$. Trinchieri). The cells were cultured in the presence of either IL-12 $(10 \mathrm{ng} / \mathrm{ml})$ plus anti-IL-4 mAb $(10 \mu \mathrm{g} / \mathrm{ml})$ or IL-4 $(50 \mathrm{ng} / \mathrm{ml})$ plus anti-IL-12 mAb $(10 \mu \mathrm{g} / \mathrm{ml})$. On day 8 , NK cells were purified from the culture with the NK Isolation Kit and adjusted to $2 \times 105 / \mathrm{ml}$ in RPM I 1640 medium supplemented with $10 \% \mathrm{FCS}$. They were mixed with purified T cells $\left(8 \times 10^{5} / \mathrm{ml}\right)$ from PBM C s from the same donor in a 5-ml polystyrene round-bottom tube and then stimulated with PM A $(25 \mathrm{ng} / \mathrm{ml})$ and ionomycin $(1 \mu \mathrm{g} / \mathrm{ml})$ for 6 hours at $37^{\circ} \mathrm{C}$. Anti-IL-5 mAb (5 $\mu \mathrm{g} / \mathrm{ml})$ or IL-5 $(100 \mathrm{pg} / \mathrm{ml})$ was added to a rel evant test tube to examine the role of IL-5.

Flow fluorocytometry. To evaluate the surface expression of CD 3, CD 56, and CD 95, PBM Cs were stained with fluorescence or biotin-labeled antibodies reactive to each molecule. To detect intracellular cytokines, brefeldin $A(10 \mu \mathrm{g} / \mathrm{ml})$ was added to the culture medium 3 hours after the initiation of PMA/ionomycin stimulation. The cells stimulated for 6 hours were stained with anti-CD 3 and anti-CD 56, then fixed and permeabilized with FACS Lysing Solution and FACS Permeabilizing Solution. The permeabilized cells were stained with relevant anti-cytokine antibodies. Samples were analyzed using FACSort with CellQuest software (Becton Dickinson). Appropriate control antibodies were used to define the background immunofluorescence of the cells.

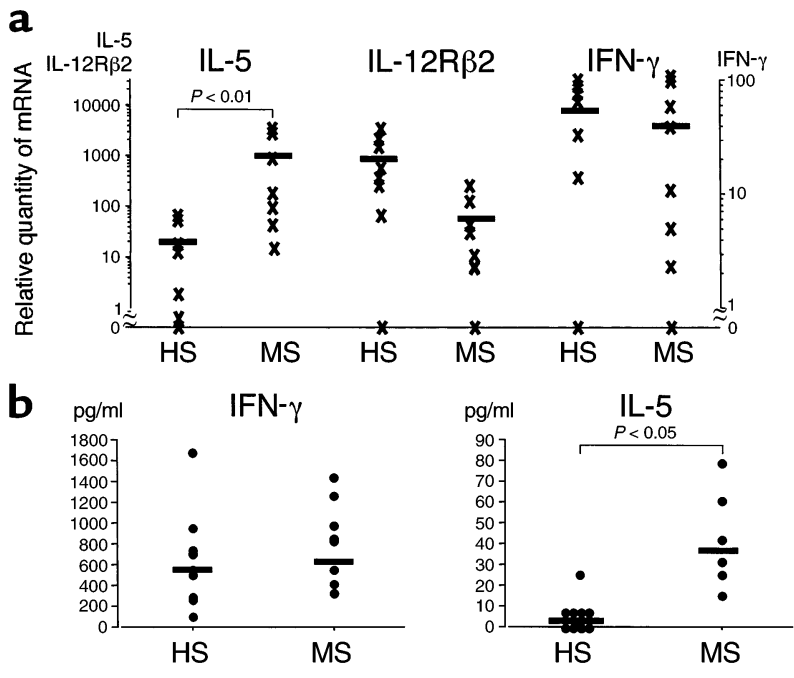

Figure 1

Cytokine production by NK cells in MS and HS. (a) Quantitative RT-PCR for IL-5, IL-12R $\beta 2$, and IFN- $\gamma$. Total RNA was isolated from NK cells obtained from patients with MS in remission and healthy subjects (HS). In the Light Cycler quantitative PCR system, the levels of gene expression are expressed by relative values as described in M ethods. (b) Quantification of IFN- $\gamma$ and IL-5 byELISA. NK cells were isolated from $\mathrm{MS}$ in remission or $\mathrm{HS}$ and stimulated with $\mathrm{PM} \mathrm{A}$ / ionomycin in 96-well U-bottom plates ( $2 \times 10^{5} /$ well). The supernatant was collected 24 hours later, and the levels of IFN $-\gamma$ and IL- 5 in the samples were determined by ELISA. M ann-Whitney $U$ test was used for statistical analysis. Horizontal bars indicate the mean values. 
Cytokine ELISA. NK cells $\left(2 \times 10^{5}\right)$ purified from PBM Cs wereeither left untouched or werestimulated with PM A/ionomycin in 96-well U-bottomed plates. IFN $-\gamma$ and IL-5 in the culture supernatants were measured by commercial kits (Endogen Inc., Woburn, M assachusetts, USA) 24 hours after initiation of the culture. The detection limit for the cytokines in this assay was $7.8 \mathrm{pg} / \mathrm{ml}$.

RT-PCR assay for cytokine measurement. For RT-PCR analysis, total RNA was extracted with RNAzol B (Biotecx Laboratories, Friendswood, Texas, USA) from purified NK cells, and the oligo (dT)-primed CD N A was prepared with the First-Strand cD N A Synthesis Kit (Amersham Pharmacia Biotech, Buckinghamshire, United Kingdom). To amplify cytokine messages, the samples were incubated for 5 minutes at $95^{\circ} \mathrm{C}$ and then subjected to 35 cycles of PCR amplification (at $94^{\circ} \mathrm{C}$ for 30 seconds, at $60^{\circ} \mathrm{C}$ for 30 seconds, and at $72^{\circ} \mathrm{C}$ for 60 seconds). For qualitative assessment, the PCR products were analyzed on $5 \%$ acrylamide gels stained with ethidium bromide. For quantitative analysis of IL -5 , IFN $-\gamma$, and IL-12R 32 , we used the Light Cycler quantitative PCR system (Roche Molecular Biochemicals, M annheim, Germany) and performed quantitative PCR with a commercial kit (Light Cycler-D N A M aster SYBR Green I) (Roche M olecular Biochemicals). The PCR amplification was repeated 40 times (at $95^{\circ} \mathrm{C}$ for 0 seconds, at $60^{\circ} \mathrm{C}$ for 5 seconds, and at $72^{\circ} \mathrm{C}$ for 10 seconds). To control the experiments, dilutions of CD N As prepared from PM A/ionomycin-stimulated PBM Cs were amplified in parallel. Based on the standard values of the control samples, the relative value for each test sample was determined with the Light Cycler software. All PCR reactions were controlled by $\beta$-actin expression, and PCR primers used were as follows: IFN- $\gamma$-sense, CAGGTCATTCAGATGTAGCG, and -antisense, GCTTTTCGAAGTCATCTCG; IL-12R $\beta 2$-sense, GGCATTTTCTCAACGCATTACTT, and -antisense, TGGATCTGGAATTTCTCTGCTACA; IL-5-sense, GCACACTGGAGAGTCAAACT, and -antisense, CACTCGGTGTTCATTACACC; IL-13-sense, CAACGCTCATTGCTCTCACTTGCC, and -antisense, CCTTGTGCGG GCAGAATCCGCTCA; IL-10-sense, AGGGCACCCAGTCTGAGAACA, and -antisense, CGGCCTTGCTCTTGTTTTCAC; TGF $\beta 1$-sense, TTTCGCCTTAGCGCCCACTG, and -antisense, TCCAGCCGAGGTCCTTGCGG; $\beta$-actin-sense, AGAGATGGCCACGGCTGCTT, and -antisense, ATTTGCGGTGGACGATGGAG.

\section{Results}

NK cells predominantly produce IL-5 in remission of MS. Using NK-cell populations freshly isolated from PBM Cs, we first screened the expression of cytokine and cytokine receptor genes including IFN $-\gamma$, IL-12R $\beta 2$-chain (IL-12R 32 ), IL-5, IL-13, IL-10, and TGF- $\beta 1$. Previous studies showed that human NK cells express these genes or gene products $(5,10-12)$. RT-PCR analysis revealed that mRNAs for IFN $-\gamma$,
IL-12R $\beta 2$, and IL-5 wereexpressed in the large majority of the N K cells obtained from MS in remission (M S-rem) and from heal thy subjects (HS) (Table 1), whereas the other genes were less frequently detected. O verall, this analysis did not reveal any significant difference between M S-rem and HS. N ext we performed quantitative RT-PCR measurement of IL-5, IL $-12 R \beta 2$, and IFN $-\gamma$, as expression of these genes might help us distinguish functional phenotypes of NK cells. Namely, studies have demonstrated that production of IFN $-\gamma$ and IL -5 would define N KI and NK2 cells, respectively (5) and that much higher levels of IL-12R $\beta 2$ mRN A are accumulated in NK1 than NK2 (5). The quantitative analysis revealed that the expression of IL-5 mRNA was greatly $(\sim 50$-fold $)$ enhanced in NK cells obtained from M S-rem compared with HS $(P<0.01)$ (Figure $1 a)$. In contrast, there was no difference in the level of IFN $-\gamma$ mRN A between the two groups. IL-12R $\beta 2$ tended to be lower

a
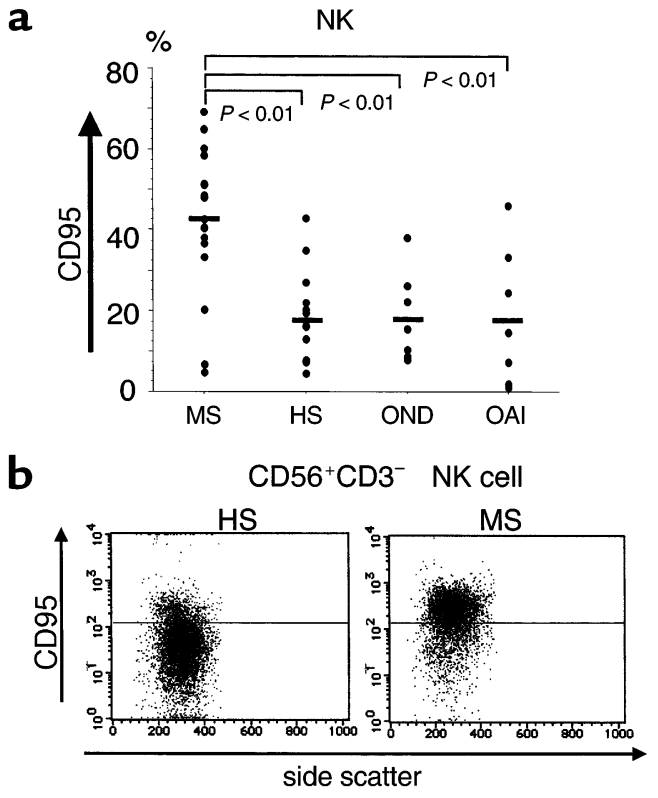

Figure 2

Surface expression of CD 95 on NK cells in M S-rem and controls. (a) Frequency of $\mathrm{CD} 95^{+} \mathrm{NK}$ cells. Freshly isolated PBM Cs were stained with anti-CD3-FITC, anti-CD56-PE, and anti-CD95-biotin/StreptavidinCychrome and were analyzed by flow fluorocytometry within 2 hours after drawing blood. The data are expressed as percentages of CD95+ cells among CD 56+CD3--gated NK cells. Controls for M S-rem include HS, patients with other neurological diseases (OND) (Parkinson disease $[n=4]$, spinocerebellar degeneration [ $n=2]$, amyotrophic lateral sclerosis [ $=1]$ ) and those with other autoimmune diseases (OAI) (thyroiditis [ $n=5]$, myasthenia gravis [ $=1]$, inflammatory demyelinating polyneuropathy $[n=1]$ ). Kruskal-Wallis test with Scheffe's $F$ test was used for statistical analysis. Horizontal bars indicate mean values. (b) CD95 expression on NK cells from M S-rem versus HS. PBM Cs were stained with anti-CD3-FITC, anti-CD56-PE, and anti-CD95biotin/Streptavidin-Cychrome. CD56+CD3- lymphocytes were gated and analyzed for CD95 expression versus side scatter. The horizontal bars indicate the fluorescence intensity distinguishing $\mathrm{CD}^{+} 5^{+}$and CD95- cells. Shown are representative data out of 20 samples (MS $[n=10], \mathrm{HS}[n=10])$ with similar results. 


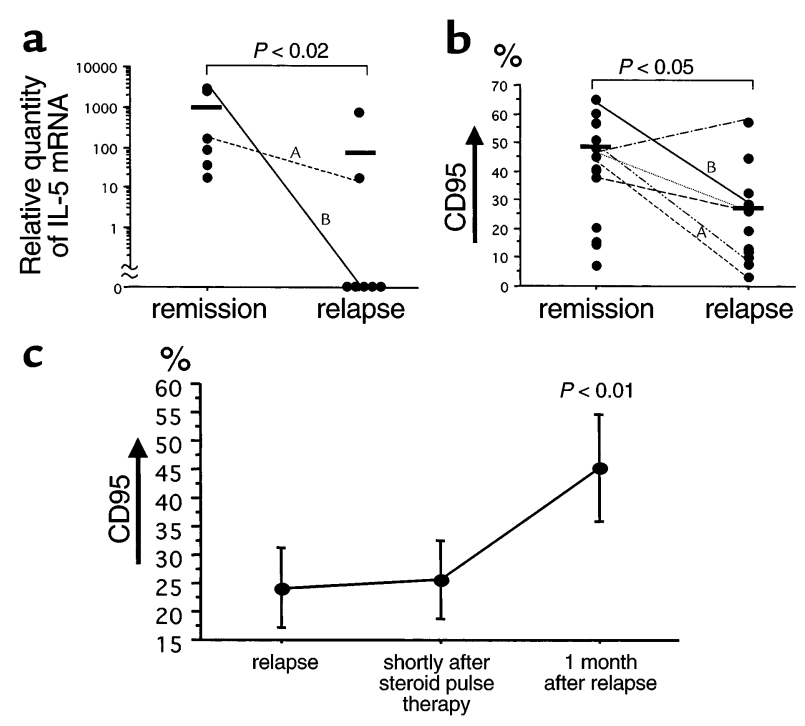

Figure 3

Characterization of NK phenotype in the clinical course of MS. (a) Reduction of IL-5 mRNA during relapse. Total RNA was isolated from NK cells and then subjected to quantitative RT-PCR analysis. The data obtained from the same patients at different stages are connected with lines. (b) Decreased frequency of CD 95+ NK cells during relapse. Freshly isolated PBMCs were stained with anti-CD3-FITC, anti-CD56-PE, and anti-CD95-biotin/Streptavidin-Cychrome and analyzed by flow fluorocytometry. The data are expressed as percentages of $\mathrm{CD} 95^{+}$cells among CD $56{ }^{+} \mathrm{CD} 3^{-}-$ gated NK cells. A,BSample pair from the same patient analyzed for these two parameters. Mann-Whitney $U$ test was used for both a and $\mathbf{b}$. (c) Increase of CD95+ NK cells after clinical recovery. The frequency of $C D 95^{+} \mathrm{NK}$ cells was determined as performed in $\mathbf{b}$. The first samples were obtained on the day of hospitalization (relapse) before starting injection of $1,000 \mathrm{mg} / \mathrm{d}$ of methylprednisolone (steroid pulse) for 3 consecutive days. The second samples were obtained 5-7 days after the start of the pulse therapy (shortly after steroid pulse therapy). The third samples were collected 1 month after the first sampling ( 1 month after relapse). Bars $=\mathrm{SE}$. Friedman test was used for statistical analysis.

in M S-rem than HS, although the difference was not significant $(P=0.14)$. These results raise a possibility that NK cells may acquire an NK2-like phenotype during remission of MS. N ext we measured thelevels of IFN $-\gamma$ and IL -5 in the supernatant of NK cells after stimulation with PMA and ionomycin (Figure $1 b$ ). Consistent with the data of thequantitativeRT-PCR, IL-5 was el evated in the supernatant of NK cells from MS-rem compared with HS ( $\mathrm{P}<0.05)$, whereas IF N- $\gamma$ was equally elevated in both groups.

NK cells expressing CD 95 (Fas) areincreased in remission of MS. The remarkableincrease of IL-5 mRNA enabled us to speculatethat NK cells might be persistently activated in theremission phase of MS. Wethereforeexamined surface expression of cell activation markers (CD 25, CD 69, and CD 95) on various cell populations in MSrem and control subjects including HS, OND, and OAI. Flow fluorocytometric analysis of NK cells (CD 56+CD 3-), CD 56+T cells (CD 56+CD 3+), and T cells $\left(C D 56-\mathrm{CD}^{+}\right)$revealed that proportions of NK cells express CD 95 (Fas) with moderate intensity and that the frequency of CD $95^{+} \mathrm{NK}$ cells was significantly elevated in M S-rem compared with controls $(P<0.01)$ (Figure 2, a and b). In contrast, there was no difference between M S-rem and the controls regarding the frequency of CD $95^{+}$cells in CD 56+ or CD 56- T cells. The surface expression of CD25 or CD 69 did not differ between M S-rem and the controls (data not shown). Because an intermediatelevel of CD 95 expression is a character of NK2 cells (5), theresults can beregarded as an additional support for occurrence of NK2-like deviation in M S-rem in vivo. In parallel, we examined the cytotoxic activity of $\mathrm{NK}$ cells targeting ${ }^{51} \mathrm{Cr}$-labeled K562 cells, but found no significant differencebetween M S-rem and HS (data not shown).

Change of NK phenotype in the clinical course of MS. We next compared MS in relapse (M S-rel) with MS-rem regarding the quantity of IL-5 $\mathrm{mRNA}$ and the frequency of CD 95+ cells in NK cells. Overall, both of the parameters were significantly depressed in NK cells obtained from MS-rel compared with those from M S-rem (Figure 3, $a$ and b). We had opportunities to examine pairs of remission and relapse samples obtained from same subjects. D ecrease of IL-5 mRN A or reduction of $C D 95^{+}$cell frequencies during relapse was confirmed in all but one pair, further supporting that the N K2-like phenotype is associated with clinical remission. In addition, weperformed a cohort study for seven patients with MS, starting on the day of hospitalization dueto a recent onset of relapse. As shown in Figure 3c, administration of high-dosemethylprednisolone for 3 consecutive days did not cause a rapid change of the CD95 expression. O ne month later, however, thefrequency of CD $95^{+} \mathrm{NK}$ cells had increased up to thelevel usually seen in MS-rem. Given that most of the patients had clinically recovered until that time, this result convinced us that an increased frequency of CD $95^{+} \mathrm{NK}$ cells is associated with clinical remission of $\mathrm{MS}$.

Regulatory function of NK1 and NK2 cells in vitro. Cytokine profiles distinguishing the NK1/N K2 subsets are similar but not identical to those for the Th1/Th2. For example, NK1 or N K2 cells produce neither IL-2 nor IL-4 (5), and NKI cells produce IL-10, a Th2 cytokine. At present, therole of N K1 or N K2 cells in the adaptive immunity remains an open question.

\section{Table 2}

Frequency of IFN $-\gamma^{+}$T cells after incubation with or without NK subset

$\begin{array}{cccc} & \text { T+NK1 } & \text { T+NK2 } & \text { T alone } \\ \text { HS-1 } & 13.71 & 7.54 & 11.52(\%) \\ \text { HS-2 } & 2.65 & 1.30 & 6.53 \\ \text { HS-3 } & 4.7 & 2.96 & 4.5 \\ \text { HS-4 } & 9.24 & 6.58 & \text { ND } \\ \text { HS-5 } & 8.03 & 4.47 & 8.60\end{array}$

We examined the effect of NK subset on the induction of intracellular IFN- $\gamma^{+}$ T cells using PBM Cs from healthy donors HS-1 to -5 . The flow cytometry data of HS-1 is shown in Figure 4, and the experimental procedure is described in the legend to Figure 4. T+NK1, T cells incubated with NK1; $T+N K 2$, T cells incubated with NK2; T alone, T cells incubated without NK cells; ND, not determined. 


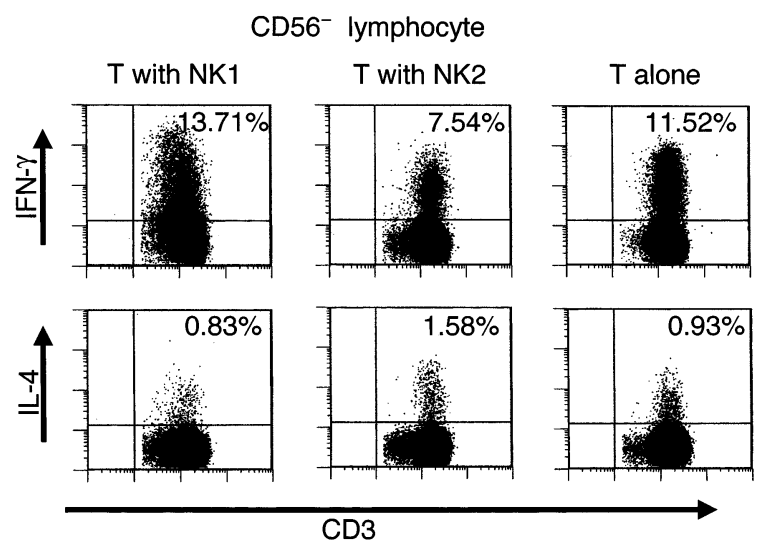

Figure 4

Intracellular staining of IFN $-\gamma$ and IL- 4 in T cells stimulated with $\mathrm{PM}$ A/ionomycin. Freshly isolated T cells $\left(8 \times 10^{5} / \mathrm{ml}\right)$ were mixed with either NK1 or NK2 cells $\left(2 \times 10^{5} / \mathrm{ml}\right)$ that had been generated from the same donor. The T/NK cell mixtures or T cells without NK cells were stimulated with PM A/ionomycin at $37^{\circ} \mathrm{C}$ for 6 hours, and the stimulated cells were stained with anti-CD3-PerCP and anti-CD56-FITC and then fixed and permeabilized. The cells were stained with either anti-IFN- $\gamma$-PE or anti-IL-4-PE, and CD 56- Iymphocytes were analyzed for expression of IFN $-\gamma$ or IL-4. The percent values shown in the upper right quadrant denote the percentages of IFN $-\gamma^{+}$or IL-4+ cells among CD56-CD3 ${ }^{+} T$ cells.

To address this problem, we generated NK1 or NK2 cells in vitro from PBMCs of HS according to the described method (5). Theinduced N K1 or NK2 Vcells were mixed with freshly isolated T cells from the same subject and stimulated with PMA/ionomycin. Intracellular expression of IFN- $\gamma$ and IL-4 was analyzed 6 hours later with flow fluorocytometry. As shown in Figure 4 and Table 2 , the frequency of IFN $-\gamma^{+} T$ cells was consistently lower in the T cells incubated with NK2 than in those incubated with NK1 or without NK cells. In contrast, the frequency of IL-4+ $\mathrm{T}$ cells was highest when incubated with NK2 in two of the five subjects, although this tendency was not clear in the other three (data not shown). These results indicate that NK2 cells would inhibit theinduction of Th1 cells but drive Th2 polarization of peripheral T cells. Autoimmune T cells mediating M S are postulated to beTh1 cells producing IFN $-\gamma$. Thein vitro experiments raised a possibility that the bias of NK cells for IL -5 production seen in MS-rem might be beneficial for maintaining the state of remission.

Involvement of IL-5 in theTh1 suppression mediated by N K 2 cells. To shed light on the mechanism by which in vitro induced NK2 cells inhibit Th1 induction, we collected culture supernatant of PMA/ionomycin-stimulated NK2 cells and examined the effect of this supernatant on the $T$ cells stimulated with PMA/ionomycin. We found that the number of IFN $-\gamma^{+} T$ cells after stimulation was reduced when incubated in the presence of the supernatant (data not shown), showing that Th1 inhibitory mediator(s) are produced by NK2 cells. Because IL-5 was most prominently expressed in N K2 cells, wenext focused on therole of IL-5 in theTh1 inhibition by the NK 2 supernatant. As shown in Figure 5, exogenous IL-5 inhibited theinduction of IFN $-\gamma^{+} \mathrm{T}$ cells after stimulation. In contrast, anti-IL-5 mAb partially abrogated the suppressive effect of the supernatant, implying that IL-5 is partly involved in the Th1 inhibition. However, neither anti-TGF- $\beta$ nor anti-IL-13 mAb abrogated the Th1 inhibitory activity (data not shown).

\section{Discussion}

NK cells wereoriginally defined as a population of lymphocytes showing ability to kill certain target cells in a non-M HC-restricted manner (13). Previous studies have correlated a reduction of NK cell cytotoxic activity with an exacerbation of autoimmune disease, although considerable controversy has remained (13). Here we focused on the cytokine profile of NK cells in MS to gain insights into theimmunoregulation of MS. We demonstrate first that NK cells in remission predominantly produce IL- 5 but express lesser amounts of IL-12R $\beta 2$ than do controls. The result indicates that theNK cells share some properties with Th2 cells $(1,14$, $15)$, in that they are capable of competing with pathogenic autoimmuneTh1 cells.

Recent studies have established theability of NK cells to produce IL-5 $(5,8,10,11)$. The published data indicate that $\mathrm{NK}$ cells could functionally polarizeinto cells predominantly producing IL $-5(5,8,10)$ and that this polarization may be augmented by IL-4 $(5,8,10)$ but inhibited by IL-10, IL-12, or IFN - $\gamma(8,10)$. However, it remained unclear whether such NK cell bias could occur physiologically in vivo. The present study shows for the first timeto our knowledgethat theNK cell bias for IL-5 production occurs in the remission of MS, a Th1-mediated autoimmune disease. Because addition of a neutralizing $\mathrm{mAb}$ to IL-5 showed a suppressive effect on the NK2-mediated Th2 deviation (Figure 5), wepresume that IL-5 produced by NK cells plays a substantial role in theimmunoregulation.

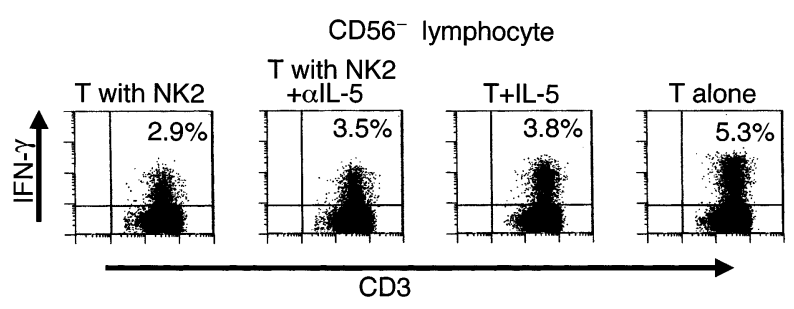

\section{Figure 5}

Involvement of IL-5 in the Th1 inhibition by NK2 cells. Freshly isolated T cells were mixed with or without NK2 cells obtained from the same donor and were stimulated with PM A/ionomycin for 6 hours as performed in the experiment in Figure 4. To ascertain the role of IL-5, a neutralizing anti-IL-5 mAb (T with NK2+ + IL-5), an isotypematched control mAb ( $T$ with NK2), or recombinant IL-5 (100 $\mathrm{pg} / \mathrm{ml}$ ) was added to the culture. The stimulated cells were permeabilized and stained with anti-human CD3-PerCP, anti-CD56-FITC, and anti-IFN $\gamma$-PE. This is a representative of two experiments with similar results. $T, T$ cells. 
Furthermore, wediscovered that NK cells in M S-rem express a higher level of CD 95 moleculeon the cell surface. Regarding the lymphocyte expression of CD 95, a previous study by Zipp et al. did not show a significant difference between MS and HS (16). This is simply because they studied T cells or total PBM Cs, but did not focus on NK cells. We could not reveal the difference in CD95 expression when we analyzed total PBMCs (data not shown). Interestingly, Zipp et al. reported a significant increase of soluble CD 95 in the serum of MS compared with HS (17). They subsequently discussed on the possibility that solubleCD 95 may inhibit the CD 95-mediated apoptosis of autoimmuneT cells. Although it remains speculative, it is possible that soluble CD 95 might play some role in protection against the CD95-mediated death of NK cells in MS. It is interesting to investigate on the biologic meaning of CD 95 expression by NK cells in thefuture.

On the basis of the predominant IL-5 production and the higher expression of CD 95, we operationally defined the NK phenotype in MS as NK2-like. Of particular note, theN K cell expression of IL-5 mRNA and CD 95 was significantly reduced during relapse of MS. It remains to be determined whether the loss of the NK2 markers preceded the onset of relapse. If the change of NK phenotype is followed by clinical relapse, it is tempting to speculate that the functional change of NK cells may play a key rolein triggering clinical exacerbation of MS. Given that relapses of MS are not always associated with infectious agents believed to stimulate autoimmuneT cells (18), this is an important issue to be further investigated. However, even if the change of NK cells is secondary to clinical exacerbation, the loss of N K2-like phenotype during relapse is likely to be an augmenting mechanism for Th1 cell-induced inflammation. To understand better the change of NK cell phenotype, weneed to evaluate more precisely on the signaling cascade leading to IL-5 production $(19,20)$.

Because NK cells are involved in various cellular interactions, the functional bias of NK cells needs to be understood in the context of the immune network. In addition to the NK2-like bias, the remission of MS is associated with a greatly reduced number of CD 1drestricted NKT cells expressing the $\alpha 24-J \alpha Q$ invariant TCR $\alpha$-chain (20). TheNKT cells are a uniquelymphocyte population that can producelarge amounts of Th1 and Th2 cytokines shortly after TCR ligation $(21,22)$. When stimulated with a glycolipid ligand, they can rapidly interact with NK cells via producing IFN $-\gamma(23,24)$. An interesting question for the future study would be whether there is some link between the N K2-like bias and NKT cell reduction seen in the remission of MS.

In additional experiments of this study, we demonstrate that in vitro-induced NK2 cells inhibit the induction of Th1 cells after stimulation with PM A/ionomycin. This result has prompted us to postulate that the NK2-like cells expressing IL-5 and CD 95 in vivo might have a potential to regulate Th1 autoimmune pathogenic $T$ cells. If the in vitro setup would faithfully ref lect critical aspects of in vivo condition, it is possible that the NK cell bias in MS in remission may contribute to the maintenance of clinical remission. As shown, IL-5 could directly inhibit the induction of Th1 cells. However, this cytokine only partly accounted for the Th1 inhibitory activities mediated by NK2 cells in vitro. Additional factors produced by NK cells are presumably involved. In addition, it is possible that the IL-5 produced by NK cells may participatein immunoregulation in a morecomplex way involving humoral immunity or eosinophils induced by IL-5.

Although a possible link between NK cells and autoimmune disease has long been suspected, the main focus of research has been directed against NK cell cytotoxic activity. Emerging roles of NK cells in immunoregulation prompt us to conduct further research into this subject. The association of NK2-like bias with MS remission indicates that immunological interventions causing such an NK bias may ben efit patients with MS. Targeting NK cells may thus develop new therapeutic strategies or protectivemeans for autoimmune diseases.

\section{Acknowledgments}

Wethank M. Ogawa and M. Kawai, M usashi H ospital, National Center of N eurology and Psychiatry, for providing clinical samples for study, and T. Tabira, $\mathrm{N}$ ational Institute of $\mathrm{N}$ euroscience, $\mathrm{N}$ ational Center of N eurology and Psychiatry, for support in the early stage of this work. We also thank Kyoko Nakata, Japan Branch of MS Cabin (International MS Support Foundation, Tokyo, Japan), for continuous help and encouragement. This work was supported by a Research on Brain Science grant from the M inistry of Health and Welfare in Japan.

1.Das, M.P., Nicholson, L.B., Greer, J.M., and Kuchroo, V.K. 1997. Autopathogenic T helper cell type1 (Th1) and protectiveTh2 clones differ in their recognition of the autoantigenic peptide of myelin proteolipid protein. J. Exp. M ed. 186:867-876.

2. Olivares-Villagomez, D., Wang, Y., and Lafaille, J.J. 1998. Regulatory CD 4(+) T cells expressing endogenous $T$ cell receptor chains protect myelin basic protein-specific transgenic micefrom spontaneous autoimmune encephalomyelitis. J. Exp. M ed. 188:1883-1894.

3. Wolf, S.D., Dittel, B.N., H ardardottir, F., and Janeway, C.A., Jr. 1996. Experimental autoimmune encephalomyelitis induction in genetically B cell-deficient mice. J. Exp. M ed. 184:2271-2278.

4. Zhang, B., Yamamura, T., Kondo, T., Fujiwara, M., and Tabira, T. 1997. Regulation of experimental autoimmune encephal omyelitis by natural killer (NK) cells. J. Exp. M ed. 186:1677-1687.

5. Peritt, D., et al. 1998. Differentiation of human NK cells into NK1 and NK2 subsets. J. Immunol. 161:5821-5824.

6. Paul, W.E., and Seder, R.A. 1994. Lymphocyte responses and cytokines. Cell. 76:241-251.

7. Abbas, A.K., M urphy, K.M., and Sher, A. 1996. Functional diversity of helper T lymphocytes. Nature. 383:787-793.

8. Hoshino, T., Winkler-Pickett, R.T., M ason, A.T., Ortaldo, J.R., and Young, H.A. 1999. IL-13 production by NK cells: IL-13-producing NK and T cells are present in vivo in the absence of IFN- $\gamma$. J. Immunol. 162:51-59.

9. Poser, C.M ., et al. 1983. N ew diagnostic criteria for multiple sclerosis: guidelines for research protocols. Ann. Neurol. 13:227-231.

10. Warren, H.S., Kinnear, B.F., Phillips, J.H., and Lanier, L.L. 1995. Production of IL- 5 by human NK cells and regulation of IL -5 secretion by IL-4, IL-10, and IL-12. J. Immunol. 154:5144-5152.

11. Walker, C., Checkel, J., Cammisuli, S., Leibson, P.J., and Gleich, G.J. 1998. IL -5 production by NK cells contributes to eosinophil infiltration in a 
mouse model of allergic inflammation. I. Immunol. 161:1962-1969.

12. M ehrotra, P.T., et al. 1998. Production of IL-10 by human natural killer cells stimulated with IL-2 and/or IL-12. J. Immunol. 160:2637-2644.

13. Trinchieri, G. 1989. Biology of natural killer cells. Adv. Immunol. 47:187-376.

14. Young, D .A., et al . 2000. IL-4, IL-10, IL-13, and TGF-beta from an altered peptideligand-specific Th2 cell clone down-regulate adoptivetransfer of experimental autoimmune encephalomyelitis. J. Immunol. 164:3563-3572.

15. Ramirez, $F$, and M ason, D. 2000. Induction of resistanceto activeexperimental allergic encephalomyelitis by myelin basic protein-specific Th2 cell lines generated in the presence of glucocorticoids and IL-4. Eur. J. Immunol. 30:747-758.

16. Zipp, F., et al. 1997. CD 95 expression and CD 95-mediated apoptosis of $T$ cells in multiplesclerosis. No differences from normal individuals and no relation to HLA-DR2. J. Neuroimmunol. 81:168-172.

17. Zipp, F., et al. 1998. Increased serum levels of solubleCD 95 (APO-1/Fas) in relapsing-remitting multiplesclerosis. Ann. N eurol. 43:116-120.

18. Wucherpfennig, K.W., and Strominger, J.L. 1995. M olecular mimicry in $\mathrm{T}$ cell-mediated autoimmunity: viral peptides activate human $\mathrm{T}$ cell clones specific for myelin basic protein. Cell. 80:695-705.
19.Zhang, D.H., Yang, L., and Ray, A. 1998. Differential responsiveness of the IL-5 and IL-4 genes to transcription factor GATA-3. J. Immunol. 161:3817-3821.

20. Lee, H.J., et al. 2000. GATA-3 induces T helper cell type2 (Th2) cytokine expression and chromatin remodeling in committed Th1 cells. J. Exp. Med. 192:105-115.

21. Illés, Z., et al. 2000. Differential expression of NK T cell V al pha 24J alpha $Q$ invariant TCR chain in the lesions of multiple sclerosis and chronic inflammatory demyelinating polyneuropathy. J. Immunol. 164:4375-4381.

22. Bendelac, A., Rivera, M .N ., Park, S.H ., and Roark, J.H. 1997. M ouseCD 1specific NK1 T cells: development, specificity, and function. Annu. Rev. Immunol. 15:535-562.

23. Exley, M., Garcia, J., Balk, S.P., and Porcelli, S. 1997. Requirements for CD 1d recognition by human invariant Val pha24+CD 4-CD 8- T cells. J. Exp. Med. 186:109-120.

24. Carnaud, C., et al. 1999. Cross-talk between cells of theinnate immune system: NKT cells rapidly activate NK cells. J. I mmunol. 163:4647-4650.

25. Eberl, G., and M acD onald, H.R. 2000. Selectiveinduction of NK cell proliferation and cytotoxicity by activated NKT cells. Eur. J. Immunol. 30:985-992. 